\title{
PERAN KEPALA SEKOLAH BERDASARKAN KEPEMIMPINAN KRISTEN YANG MENOLONG GURU SDTK KASIH KARUNIA KUPANG UNTUK MEMILIKI DISIPLIN ROHANI
}

\author{
Azalia Elmaivana Jovita \\ Program Studi Pendidikan Guru Sekolah Dasar, \\ Universitas Kristen Petra \\ J1. Siwalankerto 121-131, Surabaya \\ E-mail: g11170006@john.petra.ac.id
}

\begin{abstract}
ABSTRAK
Kepemimpinan Kristen adalah kepemimpinan yang berlandaskan pada nilai-nilai Kristiani dan yang menjadikan Kristus sebagai teladan. Di sekolah Kristen yang menjadi pemimpin adalah kepala sekolah. Kepala sekolah SDTK Kasih Karunia Kupang sudah menjalankan peran pemimpin Kristen dalam menolong guru memiliki disiplin rohani sebagai pendidik, pemberi motivasi, dan pemimpin. Kepala sekolah memandang disiplin rohani sebagai hal yang penting, maka dari itu kepala sekolah harus membuat program yang menunjang disiplin rohani dan didukung oleh tindakan secara langsung. Penelitian ini bertujuan untuk mendeskripsikan peran kepala sekolah berdasarkan kepemimpinan Kristen untuk menolong guru memiliki disiplin rohani. Penelitian ini menggunakan pendekatan kualitatif deskriptif. Pengumpulan data yang dilakukan adalah observasi, peneliti melakukan observasi sebanyak 2 tahap. Tahap pertama dilakukan pada tanggal 11 Januari - 24 Januari, dan tahap kedua dilakukan dari bulan November - Desember. Pengumpulan data juga dilakukan secara wawancara, yang menjadi narasumber adalah kepala sekolah dan 3 orang guru SDTK Kasih Karunia Kupang. Hasil penelitian ini menunjukkan bahwa kepala sekolah telah menjalankan tiga peran sebagai pendidik, pemberi motivasi dan pemimpin. Dari ketiga peran tersebut dapat menolong guru untuk memiliki disiplin rohani.
\end{abstract}

Kata kunci: kepemimpinan kristen, pendidik kristen, pemberi motivasi kristen, dan pemimpin kristen.

\begin{abstract}
Christian leadership is a leadership that is based on Christian values. It places Christ as an example. In Christian schools, the leader is the principal. The principal of SDTK Kasih Karunia Kupang has carried out the role of Christian leaders in helping teachers have spiritual discipline as educators, motivators, and leaders. The principal views spiritual discipline as important, and therefore makes a program that supports spiritual discipline and directs action to exercise spiritual discipline. This study aims to describe the role of school principals based on Christian leadership to help teachers have spiritual discipline. This study uses a descriptive qualitative approach. The data collection was carried out by observing, the researchers conducted observations in 2 stages. The first stage was carried out on January 11 - January 24, and the second stage was carried out from November - December. The author collects the data from interviews with the school's principal and three teachers of SDTK Kasih Karunia, Kupang. The results of this study indicate that the principal has carried out three roles as educators, motivators, and leaders. These three roles can help teachers to have spiritual discipline.
\end{abstract}

Keywords: christian leadership, christian educator, christian motivator and christian leader

\section{a. PENDAHULUAN}

Kepemimpinan Kristen adalah kepemimpinan yang berlandaskan pada nilai-nilai Kristiani dan menjadikan Kristus sebagai teladan. Di sekolah Kristen yang menjadi pemimpin adalah kepala sekolah. Kepala sekolah memiliki tanggung jawab yang penting dalam memimpin. Namun realitanya saat ini, beberapa kepala sekolah
Kristen belum sepenuhnya menjalankan peran sebagai pemimpin. Dilansir dari Kabartimurnews.com ("Komite bakal lapor kepsek SD Kristen Soindat", January 26, 2020), seorang pemimpin di sebuah sekolah dasar Kristen di Kabupaten Maluku Tenggara akan dilaporkan oleh Komite Sekolah karena kurang bertanggung jawab atas perannya dalam memimpin. Sebagai seorang kepala sekolah Kristen, beliau tidak menjalankan 
perannya dalam menolong guru dalam aspek apa pun. Sebaliknya ia jarang hadir di sekolah. Hal ini menunjukkan adanya kegagalan dalam menjalankan peran kepala sekolah Kristen sebagai pemimpin Kristen.

Idealnya, peran kepemimpinan kepala sekolah Kristen sangat penting. Gibbs (2010) mengutip dari Robert Clinton, pemimpin Kristen adalah seseorang yang mendapat kapasitas dan tanggung jawab dari Allah untuk memberi pengaruh kepada kelompok umat Allah tertentu untuk menjalankan kehendak Allah bagi kelompok tersebut. Hal ini menunjukkan bahwa kepala sekolah Kristen harus menjadi teladan untuk menginspirasi guru. Dengan demikian, guru dapat mengikuti teladan kepala sekolah Kristen. Selanjutnya guru bisa menjalankannya dan menjadi contoh untuk murid.

Salah satu teladan yang bisa ditunjukkan kepala sekolah Kristen adalah dalam hal kedisiplinan rohani. Disiplin rohani adalah kegiatan sendiri maupun bersama yang mereka lakukan sebagai cara untuk menempatkan diri kita di hadapan Tuhan agar Ia dapat bekerja di dalam diri kita. Kedisiplinan rohani yang dimaksud seperti berdoa, beribadah, memberitakan Injil, melayani, berpuasa dan semua kegiatan yang menolong warga sekolah menjadi serupa dengan Kristus (Foster,1990). Maka dari itu sangat penting peran kepala sekolah Kristen dalam memfasilitasi kedisiplinan rohani warga sekolah khususnya guru. Namun sebelum itu, kepala sekolah Kristen perlu untuk menerapkan kedisiplinan rohani terhadap dirinya. Hal ini sejalan dengan pendapat yang dikemukakan oleh Starratt \& Guare (1995), sebagai pemimpin yang menerapkan disiplin rohani, kepala sekolah Kristen juga harus menerapkan itu terhadap dirinya.

Penelitian ini dilakukan di Sekolah Dasar Teologi Kristen Kasih Karunia Kupang. Alasan peneliti memilih sekolah ini karena berada di daerah yang terpencil, tidak banyak orang mau melakukan penelitian di daerah Kupang. Sekolah ini menerapkan pendidikan dan kepemimpinan Kristen walaupun di tempatnya sulit untuk mendapatkan jaringan internet. Ini merupakan alasan yang penting dari penelitian ini karena sekolah ini menerapkan pendidikan dan kepemimpinan yang meneladani Kristus. Berharap, banyak sekolah Kristen yang mau menerapkan pendidikan dan kepemimpinan Kristen atau yang meneladani Kristus. Selanjutnya, subjek yang diambil oleh peneliti yaitu kepala sekolah dan guru. Penelitian ini ingin mendeskripsikan peran kepala sekolah berdasarkan kepemimpinan Kristen menolong guru SDTK Kasih Karunia untuk memiliki disiplin rohani. peneliti.

\section{b. LANDASAN TEORI}

\subsection{Peran Kepala Sekolah}

Menurut Mulyasa (2013), kepala sekolah memiliki peran sebagai berikut : educator, motivator, dan leader. Berikut penjelasan mengenai peran dari kepala sekolah lebih spesifiknya :

\section{Kepala sekolah sebagai educator (pendidik)}

Peran kepala sekolah sebagai pendidik yang paling terpenting adalah membangun relasi dan memberikan teladan atau contoh. Dengan membangun relasi akan lebih mudah menolong kepala sekolah dalam mengenal maupun membantu rekan-rekan kerjanya. Kepala sekolah memberikan teladan melalui sikap dan perilakunya, termasuk dalam hal berpenampilan secara fisik dalam bekerja. Dalam perannya, kepala sekolah juga bertanggung jawab akan kebutuhan guru di sekolahnya. Kepala sekolah wajib membuka telinga untuk mendengarkan sukacita, tantangan dan hambatan yang dialami oleh guru (Trail, 2000). Selain itu, kepala sekolah harus memposisikan diri untuk menolong guru menghadapi perubahan musim pembelajaran.

2. Kepala sekolah sebagai motivator (pemberi motivasi)

Sebelum kepala sekolah menjadi motivator, maka dirinya sendiri harus menjadi seseorang yang memiliki motivasi. Dalam menjalankan perannya sebagai motivator, kepala sekolah mampu menyemangati guru dan staf agar mereka memiliki motivasi yang benar dalam bekerja dan mencapai tujuan sekolah. Oleh karena itu, adanya peran kepala sekolah dalam meningkatkan motivasi guru (Karwati \& Priansa, 2013) :

a. Menerapkan manajemen yang terbuka

b. Memberikan deskripsi setiap tugas dan tanggung jawab dengan jelas.

c. Menerapkan hubungan vertikal ke bawah.

d. Memiliki program dan kegiatan dalam meningkatkan motivasi guru.

e. Melakukan pengawasan yang holistik

f. Melakukan evaluasi.

3. Kepala sekolah sebagai leader (pemimpin)

Pemimpin pendidikan atau kepala sekolah diharapkan memiliki beberapa kompetensi antara lain :

a. Memfasilitasi penyusunan, penyebarluasan, pelaksanaan visi dan misi sekolah yang dikomunikasikan dengan baik dan didukung oleh sekolah 
b. Menolong, membina, dan mempertahankan lingkungan sekolah dan program pembelajaran yang kondusif bagi pembelajaran murid dan pertumbuhan profesional guru dan staf.

c. Memastikan adanya lingkungan sekolah yang kondusif dan sehat, agar memungkinkan para guru untuk mengembangkan potensi yang dimilikinya.

d. Menjamin bahwa manajemen organisasi dan pengoperasian sumber daya sekolah digunakan untuk menciptakan lingkungan belajar yang aman, sehat dan efisien.

\section{2. Peran Kepala Sekolah Berdasarkan Kepemimpinan Kristen}

Kepemimpinan Kristen adalah orang Kristen yang dipimpin oleh kasih Kristus yang berdedikasi untuk melayani, berdasarkan prinsip Alkitab yang telah dipelajari (Panekenan, 2020). Prinsip-prinsip kepemimpinan Kristen yang meneladani Kristus :

a. Fokus kepada jiwa (manusia).

Yesus sangat berorientasi pelayanannya kepada jiwa atau manusia. Ia sangat mengasihi manusia yang diciptakanNya, rela datang ke dunia untuk bertemu mereka secara pribadi.

\section{b. Fokus kepada tujuan.}

Tujuan Yesus datang ke dunia ialah untuk mencari dan menyelamatkan yang terhilang (Lukas 19.10). Yesus mengerti akan tujuannya Ia datang ke dunia, tapi Ia memiliki waktu yang sedikit untuk menyelesaikannya. Maka dari itu, Ia mempersiapkan murid-murid-Nya untuk meneruskan setiap tujuan yang telah ditetapkan-Nya. Tujuan yang diteruskan kepada murid-murid-Nya telah tertulis dalam Matius 28:19-20.

c. Pelayanan yang berpusat kepada
Alkitab

Ia datang ke dunia ini untuk bisa melayani orang-orang yang dikasihi-Nya. Banyak pelayanan yang Tuhan lakukan: menyembuhkan orang sakit, membuat mujizat, mengusir setan, dan lain-lain. Alkitab adalah bukti nyata dari apa yang Tuhan sudah lakukan di dunia ini. Benang merah dari Alkitab itu mengenai Yesus yang menjadi satu-satuNya Allah dalam dunia ini.

Menurut Korac-Kakabadse, Kouzmin, \& Kakabadse (2002), bagian penting dari peran kepala sekolah berdasarkan kepemimpinan Kristen sebagai berikut:

1. Kepala sekolah sebagai pemimpin Kristen harus memiliki karakter Kristus dalam hidupnya. Artinya dalam memimpin harus memiliki integritas, melawan setiap hal-hal di luar kebenaran Alkitab.

2. Kepala sekolah sebagai pemimpin Kristen harus memiliki waktu yang utuh bersama dengan Tuhan untuk menjalankan disiplin rohani. Dengan menjalankan disiplin rohani, akan menolong kepala sekolah untuk mengerti kehendak Tuhan dan semakin mengalami pertumbuhan rohani. Persekutuan dengan Tuhan menolong pemimpin Kristen untuk semakin mengenal Tuhan dan teladannya.

3. Kepala sekolah sebagai pendidik Kristen harus memberikan kesaksian hidupnya. Ia bisa membagikan kesaksian mengenai pertolongan Tuhan dalam memimpin hidupnya.

\subsection{Analisis Peran Kepala Sekolah Secara Umum dan Berdasarkan Kepemimpinan Kristen}

Ada dua perbedaan utama mengenai kepala sekolah secara umum dan kepemimpinan Kristen :

a. Fokus

Kepala sekolah yang menerapkan kepemimpinan Kristen memiliki fokus untuk menolong sesamanya. Hal ini berbanding terbalik dengan kepala sekolah pada umumnya yang memiliki fokus pada hasilnya seperti profesionalitas dan bertanggung jawab. Dalam konteks ini, kepala sekolah melihat dan menyadari pentingnya disiplin rohani bagi guru-guru. Dengan demikian, kepala sekolah menyadari sangat perlu untuk menolong rekan kerjanya dan bukan hanya sekedar menuntut hasil yang dapat dilihat. Kepala sekolah seharusnya memperhatikan setiap proses yang dilalui untuk menjangkau dan membimbing jiwa-jiwa yang terhilang bagi Kristus.

b. Tujuan

Kepala sekolah yang menerapkan kepemimpinan Kristen memiliki tujuan untuk menyatakan tujuan Allah sedangkan kepala sekolah secara umum memiliki tujuan pribadi. Dalam hal disiplin rohani, kepala sekolah harus mengetahui betapa pentingnya disiplin rohani itu. Hal ini merupakan sesuatu yang penting karena disiplin rohani memiliki tujuan untuk mengalami pertumbuhan rohani dan menjadi semakin serupa dengan Kristus. Dengan kata lain disiplin rohani merupakan tujuan Allah yang diberikan kepada manusia untuk bisa selalu berelasi dengannya. Dengan demikian kepala sekolah harus menyadari bahwa disiplin rohani memiliki dampak yang besar terhadap murid yaitu mengenalkan Kristus dalam kehidupan mereka. Maka dari itu, melihat dampak yang sangat besar kepala sekolah harus menjalankan tujuan Tuhan dalam kepemimpinannya. Oleh sebab 
itu, tujuan pribadi seperti pencitraan atau nama baik sekolah terkenal itu tidak akan ada lagi, hanya tujuan Allah saja yang harus dilakukan.

\subsection{Disiplin Rohani}

Di dalam buku disiplin rohani 10 pilar penopang kehidupan Kristen (Whitney, 1994), Whitney mengatakan bahwa disiplin rohani adalah saluran damai dan saluran segala sesuatu yang kita peroleh dari Kristus, yakni segala sesuatu yang mereka peroleh dari Kristus, yakni segala sesuatu yang memacu mereka untuk hidup suci, hidup yang sesuai dengan kemauan Yesus. Hal ini berarti merujuk pada disiplin atas perseorangan dan secara bersama-sama demi meningkatkan pertumbuhan rohani, bergaul akrab dengan Firman Tuhan, berdoa, beribadah, memberitakan Injil, melayani, tanggung jawab menggunakan waktu, berpuasa, bersaat teduh, menulis dalam buku harian, dan menekuni hal-hal rohani. Yang menjadi ayat pedoman dalam disiplin rohani ialah 1 Timotius 4.7b, 8. Keuntungan yang mereka peroleh dari disiplin rohani adalah kehidupan yang berguna, berbuah dan yang diberkati Tuhan. Saat kita melatih diri kita dengan hal rohani, maka berkat yang diterima tidak terbatas di masa sekarang sampai kekekalan. Sebagai pribadi guru Kristen akan menyadari bahwa disiplin rohani yaitu melatih diri dalam hal rohani dan harus diprioritaskan.

\section{METODE PENELITIAN}

\subsection{Desain Penelitian}

Berdasarkan data yang ada, peneliti menggunakan desain penelitian kualitatif. Peneliti menggunakan desain penelitian kualitatif untuk mengetahui dan mendeskripsikan peran kepala sekolah berdasarkan kepemimpinan Kristen dalam menolong guru SDTK Kasih Karunia Kupang untuk memiliki disiplin rohani.

\subsection{Subjek Penelitian}

Subjek pada penelitian ini adalah kepala sekolah SDTK Kasih Karunia Kupang dengan inisial FR. Selain itu ada informan penelitian, Informan berperan dalam proses triangulasi data, untuk mengkonfirmasi kebenaran data yang disampaikan oleh subjek penelitian. yang menjadi informan adalah 3 guru di SDTK Kasih Karunia Kupang, antara lain :

a. Wakil kepala sekolah bagian kesiswaan dan kepala UKS dengan inisial KA.

b. Operator TK dan SD Kasih karunia, wali kelas 4 dengan inisial RC.

c. Wali kelas 6 dan wakil kepala sekolah bagian kurikulum dengan inisial YA.

\subsection{Analisi Data}

Penelitian ini menggunakan pendekatan kualitatif. Dengan menggunakan metode observasi di sekolah, wawancara dengan subjek dan informan penelitian.

\section{HASIL DAN PEMBAHASAN}

\section{Hasil Observasi}

Observasi Awal : Pada tanggal 11-24 Januari 2020, peneliti melakukan Mission Trip di SDTK Kasih Karunia Kupang. Disana peneliti mengajar sebagai guru matematika untuk murid kelas 4, 5, dan 6 SD. Mengingat bahwa tujuan observasi awal dilakukan secara keseluruhan, maka dari itu penyampaian atau penyajian ini juga disampaikan secara keseluruhan dan tidak dalam harian:

1. Setiap pagi guru-guru dan kepala sekolah mengadakan devosi untuk memuji, menyembah Tuhan. Tak lupa juga mereka mendengarkan firman Tuhan. Setiap petugas atau orang yang melayani bergantian (termasuk guru dan kepala sekolah) sebagai pemimpin pujian atau pemain musik atau pembawa firman. Sering kali juga kepala sekolah membagikan pengalaman hidupnya mengenai firman yang telah didengar. Di setiap akhir devosi, kepala sekolah selalu mengingatkan akan tanggung jawab.

2. Guru-guru dan kepala sekolah mengadakan puasa dan berbuka bersama. Sebelum berbuka mereka mengadakan persekutuan, dimana mereka bisa saling sharing dan berbagi tentang kehidupan. Saat ada guru-guru yang sharing, kepala sekolah memberikan tanggapan dengan mendukung atau memotivasi guru tersebut. Tak lupa juga mereka akan saling mendoakan satu sama lain.

3. Di setiap pagi anak-anak memulai dengan berdoa dan guru berbagi kebenaran firman Tuhan. Guru mensharingkan kebenaran firman Tuhan dan mengenalkan Yesus kepada murid-murid. Tak lupa juga di akhir pembelajaran anak-anak diajak untuk memuji Tuhan dan berdoa sebelum meninggalkan kelas.

4. Kepala sekolah akan menegur, memberi masukan, atau mengingatkan guru jika mereka ada yang perlu diperbaiki atau perlu diingatkan. Pastinya kepala sekolah memiliki sahabat, jika memang sahabat tersebut melakukan kesalahan maka kepala sekolah tetap menegur atau mengingatkan. Jadi kepala sekolah tidak pilih kasih tapi mau merangkul semuanya.

Observasi Lanjutan : Peneliti mengikuti devosi guru-guru, yang awalnya dimulai jam 14.45WITA tapi ada sedikit perubahan dan devosi di majukan jam 14.30. Awalnya sangat susah dan banyak kendala mengenai jaringan karena memang jaringan di sana sangatlah susah. Dalam pengamatan saya selama 45 menit itu saya benar-benar melihat 
keseriusan guru-guru dalam melakukan devosi. Guru-guru sangat menghargai waktu untuk memuji, dan mendengarkan firman Tuhan. Dan guru yang memimpin devosi atau yang menyampaikan firman mereka mempersiapkan diri untuk bisa melayani di devosi. Karena mereka sangat menganggap devosi itu penting maka mereka setiap guru yang akan melayani benar-benar menyiapkan diri mereka. Selesai devosi ada rapat guru yang dilakukan, tapi saya tidak mengikuti kegiatan tersebut dikarena jaringan yang semakin memburuk.

\subsubsection{Program-program SDTK Kasih Karunia Kupang yang mendukung disiplin rohani.}

Selain itu sekolah menciptakan sebuah program lainnya yaitu persekutuan guru. Dimana persekutuan tersebut dilakukan oleh kepala sekolah, guru dan staf setiap satu bulan sekali, biasanya di akhir-akhir bulan. Persekutuan tersebut memberi kesempatan untuk kepala sekolah, guru dan staf bisa berbagi kesaksian kehidupan mereka. Selain itu juga persekutuan ini biasa diisi dengan games-games tentang Alkitab. Tak itu juga terkadang persekutuan ini dibagi dalam kelompokkelompok kecil guna untuk menceritakan yang menjadi pergumulan dan ditutup dengan saling mendoakan.

Selanjutnya ada program lain yang sekolah mendukung guru-guru untuk punya disiplin rohani yaitu menghafalkan ayat Alkitab. Disini bukan hanya kepala sekolah, guru staf saja yang melakukannya melainkan muridmurid pun diajak juga melakukannya. Jadi semua orang di lingkup sekolah diajak untuk menghafalkan ayat Alkitab baik itu dalam bahasa Indonesia maupun bahasa Inggris. Ini yang menjadi salah satu motivasi guru-guru mau menghafal ayat Alkitab karena murid-murid juga menghafal, mereka pun juga tidak mau kalah dalam menghafalkan ayat Alkitab.

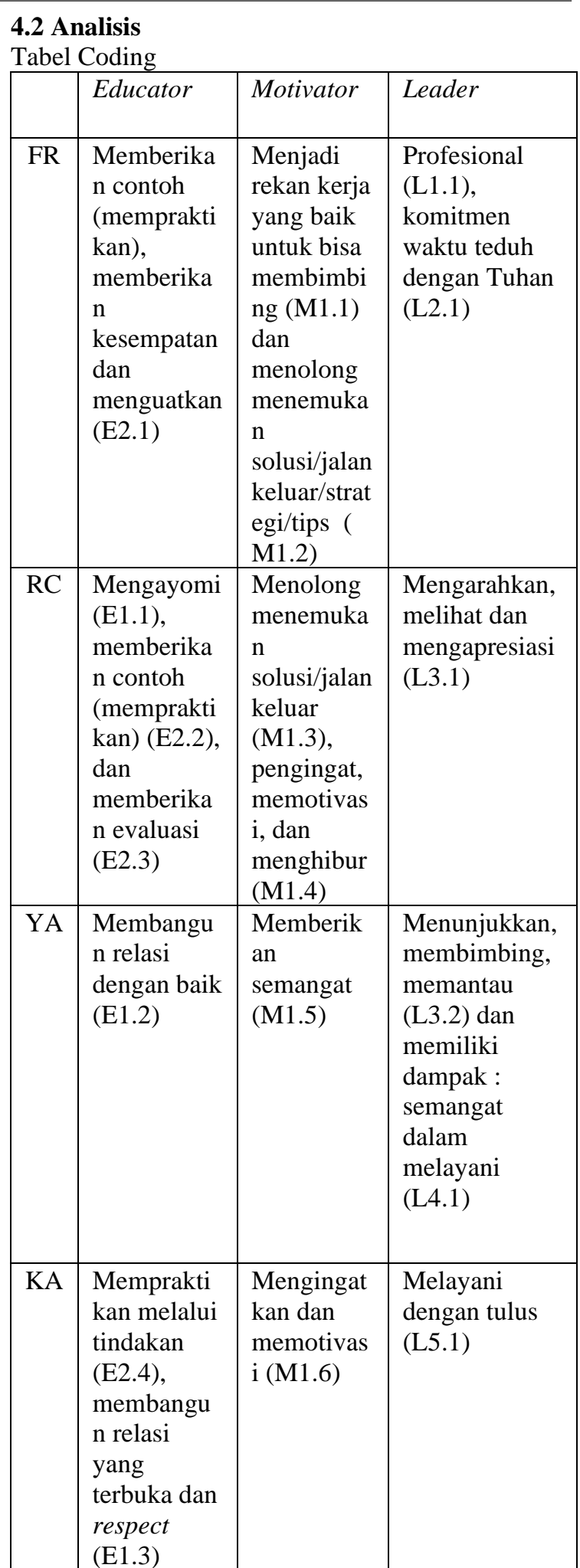

\subsubsection{Peran Kepala Sekolah Berdasarkan Kepemimpinan Kristen Dalam Menolong Guru Memiliki Disiplin Rohani}

Kepemimpinan Kristen ialah orang Kristen yang dipimpin oleh kasih Kristus yang mendedikasikan dirinya untuk melayani berdasarkan prinsip Alkitab yang telah dipelajari (Panekenan, 2020). Dalam perannya sebagai kepala sekolah yang berdasarkan kepemimpinan 
Kristen memiliki tiga prinsip-prinsip yang meneladani Kristus. Prinsip yang pertama ialah memiliki fokus

kepada jiwa (manusia) dan Prinsip yang kedua ialah fokus kepada sebuah tujuan.

"Saya memiliki pergumulan yaitu anak-anak yang kita ajar mengenal Kristus dalam hidupnya." (FR, personal communication, November 11, 2020)

Prinsip yang ketiga adalah pelayanan dan Kepala sekolah SDTK Kasih Karunia melihat apa yang sedang dikerjakan adalah suatu pelayanan. Jika pelayanan yang sedang dikerjakan tidak berlandaskan atau bersandar kepada firman Tuhan atau Yesus sendiri maka sia-sialah pelayanan itu. Karena kembali lagi pelayanan yang kita kerjakan hanya untuk kemuliaan nama Tuhan saja.

Menurut Korac-Kakabadse, Kouzmin, \& Kakabadse (2002), bagian penting dari peran kepala sekolah berdasarkan kepemimpinan Kristen sebagai berikut :

4.2.1.1 Peran Kepala Sekolah Sebagai Educator (Pendidik) Dalam Menolong Guru Memiliki Disiplin Rohani Berdasarkan Kepemimpinan Kristen

a. Kepala sekolah sebagai pendidik Kristen harus memberikan kesaksian hidupnya. Ia bisa membagikan kesaksian mengenai pertolongan Tuhan dalam memimpin hidupnya. (E1)

b. Guru merasakan bahwa kepala sekolah mengayomi dan membangun relasi yang baik "kalau mau digambarkan sebagai pimpinan dan bawahan tidak terlalu seperti itu lebih khususnya punya hubungan yang bukan saja merangkap sebagai pimpinan namun juga membantu mengarahkan. Jadi hubungannya lebih kepada pemimpin yang mengayomi seperti itu. Jadi bukannya hanya membatasi diri sebagai pimpinan apa pun yang diperintahkan itu harus dilakukan tapi kadang mengayomi, tidak terbatas atau terhalang dengan tembok pimpinan dan bawahan tapi lebih kepada memiliki komunikasi yang baik, relasi yang baik dan tidak sungkan-sungkan lagi terbuka satu sama lain." (RC, personal communication, November 4, 2020)

Guru merasakan bahwa relasi yang dibangun kepala sekolah membuat terbuka dan respect "Dan relasi saya dengan dia baik, kita itu kadang ada waktu dimana pimpinan sama bawahan terus ada kakak sama adik terus ada dimana kek teman, sahabat kek gitu. Jadi relasi yang kepala sekolah bangun dengan baik itu akan mudah menolong kami para guru untuk terbuka dan respect. Jika bisa digmbarkan relasi berdua baik sih teman bercanda juga, teman bercerita juga, " (KA, personal communication, November 6, 2020)

Setiap orang pastinya sangat menginginkan adanya sebuah perubahan atau transformasi dari dirinya. Kepala sekolah SDTK Kasih Karunia Kupang, ia juga memiliki kerinduan untuk menolong guru-guru bisa mengalami perubahan. Sebelum kepala sekolah ingin merubah guru-guru, ia harus memulai terlebih dahulu dalam dirinya. Kepala sekolah melakukan itu secara langsung dan menjadi contoh bagi guru-guru. Dari contoh itu, beliau memberikan kesempatan untuk setiap guru bisa mengalami perubahan pada dirinya. Tak hanya itu, kepala sekolah juga akan mengevaluasi atau mengoreksi jika dirasa ada yang tidak sesuai guna untuk pertumbuhan. Dan dalam konteks ini, kepala sekolah menolong guru untuk bisa memiliki perubahan dalam menjalankan disiplin rohani.

4.2.1.2 Peran Kepala Sekolah Sebagai Motivator (Pemberi Motivasi) Dalam Menolong Guru Memiliki Disiplin Rohani Berdasarkan Kepemimpinan Kristen

a. Kepala sekolah sebagai motivator Kristen harus mendukung rekan-rekan kerja (guru atau staf). Maksud dari point ini adalah mendukung atau memotivasi rekan kerja untuk menjalankan disiplin rohani.

4.2.1.3 Peran Kepala Sekolah Sebagai Leader (Pemimpin) Dalam Menolong Guru Memiliki Disiplin Rohani Dalam Kepemimpinan Kristen

b. Kepala sekolah sebagai pemimpin Kristen harus memiliki karakter Kristus dalam hidupnya. Artinya dalam memimpin harus memiliki integritas, melawan setiap hal-hal di luar kebenaran Alkitab/Firman Tuhan.

"Sayangnya, integritas merupakan komoditi yang mulai lenyap pada zaman sekarang. Standar pribadi sedang runtuh di dunia yang mati-matian mengejar kesenangan pribadi dan jalan pintas menuju sukses"

Ini merupakan salah satu hal yang diujikan dalam menjadi pemimpin, bagaimana kepala sekolah harus bisa profesional dan memiliki integritas.

c. Kepala sekolah sebagai pemimpin Kristen harus memiliki waktu yang utuh bersama dengan Tuhan untuk menjalankan disiplin rohani. Dengan menjalankan disiplin rohani, akan menolong kepala sekolah untuk mengerti kehendak Tuhan dan semakin mengalami pertumbuhan rohani.

"Kalau disiplin rohani dinilai 1-10 itu saya memilih 10 itu karena memang disiplin rohani itu sangat penting bagi diri saya. Kalau saya tidak memprioritaskan kerohanian saya maka pelayanan yang Tuhan percayakan kepada saya bisa hancur. Saya melihat bahwa apa yang saya kerjakan itu suatu bentuk pelayanan saya kepada Tuhan. Karena kerohanian itu yang paling utama dan penting bagi saya. " (FR, personal communication, November 11, 2020) 
Kepala SDTK Kasih Karunia Kupang, menyadari bahwa waktu bersama dengan Tuhan itu adalah sesuatu yang sangat penting. Itu sangat bisa dibuktikan dengan ia menilai disiplin rohani sesuatu yang penting dan diberikan nilai 10. Setiap pagi kepala sekolah akan mengambil waktu untuk bersaat teduh, berdoa dan membaca Alkitab. Maka dari itu kepala sekolah mengajak supaya guru-guru juga memiliki waktu teduh sendiri bersama dengan Tuhan.

d. Kepala sekolah sebagai pemimpin Kristen haruslah memiliki pengaruh yang baik kepada pengikut atau rekan kerjanya. Sebagai pemimpin, wajib memberikan bimbingan kepada pengikut atau rekan kerjanya untuk memiliki disiplin rohani.

Guru merasakan dampak atau pengaruh dari kepala sekolah yaitu bersemangat dalam melayani "Saya merasa termotivasi untuk melakukan pelayanan di sekolah dengan semangat dan bersahabat dengan setiap guru." (YA, personal communication, November 5, 2020)

Seorang pemimpin, selaku kepala sekolah SDTK Kasih Karunia Kupang memiliki peran untuk bisa berdampak bagi guru-guru. Setiap hal apa pun yang kepala sekolah lakukan atau berikan memiliki dampak tersendiri bagi guru. Salah satu halnya, kepala sekolah hadir dan memberikan motivasi membuat guru lebih bersemangat dalam melayani murid-murid. Begitu pentingnya seorang kepala sekolah untuk bisa membawa pengaruh atau dampak yang positif bagi guru maupun murid.

e. Fokus dari kepala sekolah sebagai pemimpin Kristen adalah mau melayani sesama. Siapapun orang yang membutuhkan bantuannya dimana pun tempatnya, pemimpin harus mau melayani mereka.

\subsection{Prinsip Dan Peran Kepala Sekolah Berdasarkan Kepemimpinan Kristen Yang Menolong Guru Memiliki Disiplin Rohani Melalui Prinsip Yang Meneladani Kristus}

Di dalam prinsip meneladani Kristus ada 3 prinsip yang kepala sekolah telah terapkan. Prinsip yang pertama mengenai fokus kepada jiwa (manusia), kepala sekolah SDTK Kasih Karunia Kupang memprioritaskan dirinya untuk bisa menolong guru maupun murid yang ada. Dia mau turun langsung

\section{KESIMPULAN}

Sesuai tujuan penelitian di awal, yaitu untuk mendeskripsikan peran kepala sekolah berdasarkan kepemimpinan Kristen menolong guru SDTK Kasih Karunia untuk memiliki disiplin rohani. Dari hasil penelitian, peneliti menyimpulkan bahwa kepala sekolah SDTK Kasih Karunia Kupang menjalankan peran kepemimpinan Kristen sebagai educator, motivator dan leader dalam menolong guru memiliki disiplin rohani. Peran yang pertama sebagai educator (pendidik), ia telah memberikan contoh atau praktik secara langsung dan memberikan dampak untuk guru bisa terbuka serta respect. Peran kedua sebagai motivator (pemberi motivasi), kepala sekolah sudah memberikan dukungan/semangat, membimbing bahkan menolong memberikan solusi/jalan keluar/strategi/tips. Dan peran yang ketiga sebagai leader (pemimpin), kepala sekolah telah profesional, memiliki waktu teduh dengan Tuhan, mengarahkan, berdampak dan mau melayani.

\section{DAFTAR REFERENSI}

Foster, R, J. (1990). Tertib rohani sudahkah anda menapakinya? Penerbit Gandum Mas.

Wawancara menurut para ahli, syarat, tujuan, jenis terlengkap!. (2020, July 20). https://fungsi.co.id/wawancara-menurut-para-ahli/

Gibbs, E. (2010). Kepemimpinan Gereja masa mendatang. BPK Gunung Mulia

Hasibuan, M. (2001). Manajemen Sumber Daya Manusia. Jakarta: Bumi Aksara.

Hidayat, A. (2012, October 14). Penelitian kualitatif: Penjelasan lengkap. https://www.statistikian.com/2012/10/penelitiankualitatif.html\#Pengertian_Penelitian_Kualitatif_Me nurut_Ahli_Pakar

Hidayati, R., Aunurrahman, \& Radiana, U. (2016). Kepemimpinan kepala sekolah dalam upaya meningkatkan kinerja guru di SD Negeri 67 Sungai Raya. Jurnal Pendidikan dan Pembelajaran Khatulistiwa, $\quad 5(5), \quad 1-18$. https://jurnal.untan.ac.id/index.php/jpdpb/article/vie w/15453

Komite bakal lapor kepsek SD Kristen Soindat. (2020, January 26). Kabartimur News . https://www.kabartimurnews.com/2020/01/26/komit e-bakal-lapor-kepsek-sd-kristen-soindat/

Karwati, E. dan Priansa, J. (2013). Kinerja dan profesionalisme kepala sekolah. Alfabeta

Korac-Kakabadse, N., Kouzmin, A., \& Kakabadse, A. (2002). Spirituality and leadership praxis. Journal of Managerial Psychology, 17(3), 165-182.

https://doi.org/10.1108/02683940210423079

Moleong, L.J. (2001). Metodologi penelitian kualitatif. PT. Remaja Rosdakarya

Mulyasa, E. (2013). Manajemen dan kepemimpinan kepala sekolah. Bumi Aksara.

Panekenan, M. (2020). Pola kepemimpinan Kristen menurut Injil Yohanes 13: 1-20. Educatio Christi, 1(1), 41-52. https://ejournal.teologiukit.ac.id/index.php/educatio-christi/article/view/9

Pengertian observasi menurut para ahli: Jenis, tujuan dan manfaatnya. (2020, Juny 9). https://www.ngelmu.co/pengertian-observasi/

Silalahi, U. (2012). Metode penelitian social. PT. Refika Aditama 
Staratt, R. J. \& Guare, R. E. (1995).

The spirituality of Leadership. Planning and Changing. 26. 190-222.

Suharsimi, A. (2010). Prosedur penelitian suatu pendekatan praktik. Rineka Cipta

Trail, K. (2000). Taking the lead: The role of the principal in school reform. CSRD Connections, 1(4), 1-8. http://files.eric.ed.gov/fulltext/ED451604.p df

Wahjosumidjo. (1998).

Kepemimpinan dan motivasi. Ghalilea Indonesia

Whitney, D. (1994). Disiplin rohani : 10 pilar penopang kehidupan Kristen. (1nd ed). Lembaga Literatur BA 